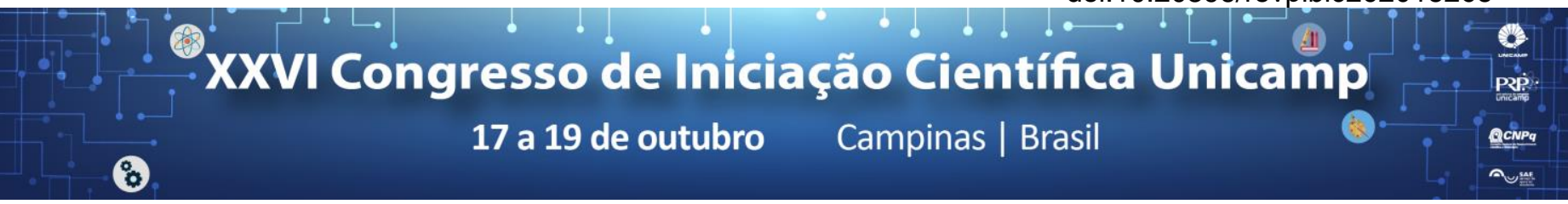

\title{
Special Optical Fibers and 3D Printed Samples using Functional Polymeric Filaments
}

\section{Carina Reis T. Avelar*,Luiz Evaristo, Bruno O. Ferreira, Cristiano M. B. Cordeiro.}

\section{Resumo}

On this work we studied the extrusion of functionalized ABS (Acrylonitrile butadiene styrene) filaments for photonic devices. The main target applications were the production of special polymer optical fibers doped with Rhodamine dye and metallic nano-particles and the fabrication of 3D printed functional samples.

\section{Palavras-chave:}

$3 D$ printing, addictive manufacturing, optical fiber, polymer fiber, plasmonics, extrusion.

\section{Introdução}

Para a execução da impressão 3D, é necessário ter filamentos à disposição. Para isso, conforme indica o esquema da figura 1 , é feito um líquido com $A B S$ e acetona. Posteriormente, acrescenta-se à este líquido o composto químico chamado rodamina e também nanopartículas de ouro em algumas amostras, terminando assim a etapa da dopagem. É necessário secar esta mistura para colocá-la na máquina extrusora, aonde o filamento é fabricado e a partir de então utilizado em dois processos distintos.

O primeiro deles, é a impressão 3D propriamente dita, que por meio deste material executa pequenos cubos que, após a aplicação do laser verde (543nm) adere uma coloração amarelada.

Alternativamente, os filamentos também podem ser utilizados em preformas produzidas com CNC para análise do comportamento deste compósito.

\section{Resultados e Discussão}

Foram analisados os comportamentos de cinco misturas diferentes após a aplicação do laser verde, uma delas apenas com ABS, além do mesmo junto com $2 \mathrm{ml}$ de rodamina, $1 \mathrm{ml}$ de rodamina, $2 \mathrm{ml}$ de rodamina e $1 \mathrm{ml}$ de nano partícula de ouro e por último $1 \mathrm{ml}$ de rodamina e 1 $\mathrm{ml}$ de nanopartícula ouro. Ao observar o gráfico, nota-se um pico na curva rosa, um pouco antes do comprimento de onda de $560 \mathrm{~nm}$, isso acontece pois é o momento de aplicação do laser verde.

As curvas traçadas com os dados captados pelo Ocean Optics, mostradas no primeiro gráfico da figura 2, indicam que a maior intensidade medida para um mesmo comprimento de onda ocorre quando há a aplicação de 2 $\mathrm{ml}$ de rodamina. Em contrapartida, o ABS puro apresenta o menor desempenho, nessa condição a microestrutura não muda sua coloração se mantendo verde, e o segundo menor é o ABS com $1 \mathrm{ml}$ de rodamina e $1 \mathrm{ml}$ de ouro. Estes gráficos refletem o comportamento da peça impressa com a mistura dos materiais funcionais ao aplicar o laser verde, conforme mostrado na figura 3 .

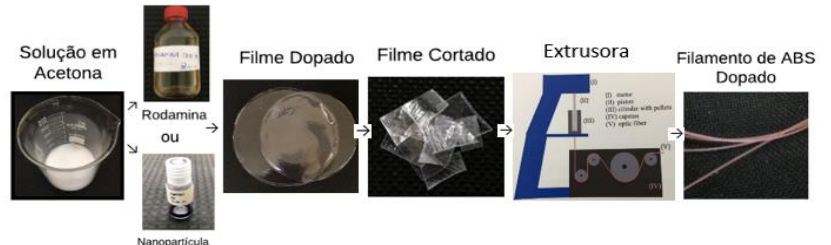

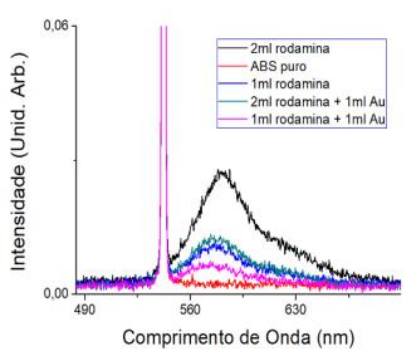

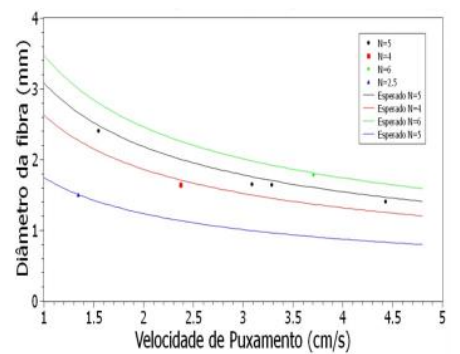

Figura 2. Intensidade da coloração amarela pelo comprimento de onda $(\mathrm{nm})$ e diâmetro da fibra $x$ velocidade do motor da extrusora, respectivamente.

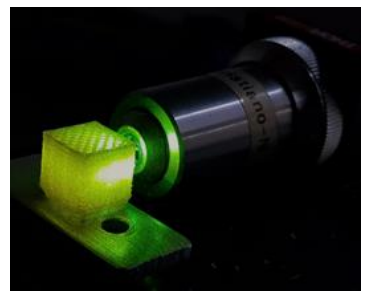

Figura 3. Momento de aplicação do laser verde.

\section{Conclusões}

Portanto, foi possível observar que a aplicação do ouro causou uma diminuição na intensidade da coloração amarela comparado a microestrutura apenas com a rodamina, que pelo outro lado, gerou um aumento desta intensidade, por sua quantidade ser proporcional a esta luminescência. Apesar de estar bem encaminhado, o puxamento da preforma para produção de fibra óptica contínua em processo de geração de dados para serem analisados.

\section{Agradecimentos}

Gostaria de agradecer ao Instituto de Física "Gleb Wataghin", ao aluno Igor Bassetto e o Professor Dr. Eduardo P. Okabe.

1 J. C. Knight, T. A. Birks, P. St. J. Russell, and D. M. Atkin, "All-silica single-mode optical fiber with photonic crystal cladding," Opt. Lett. 21, 1547-1549 (1996)

Figura 1. Fabricação das fibras 